\title{
ADDRESSING THE CHALLENGES OF A QUARTER CENTURY OF GISCIENCE EDUCATION: A FLEXIBLE HIGHER EDUCATION CURRICULUM FRAMEWORK
}

\author{
Bert Veenendaal \\ Department of Spatial Sciences, Curtin University, GPO Box U1987, Perth, Australia - b.veenendaal@curtin.edu.au
}

Midterm Symposium ISPRS Commission VI

KEY WORDS: GIS, geographic information science, GIScience, geospatial, higher education, curriculum, education development, higher education challenges, curriculum framework

\begin{abstract}
:
A wide range of geographic information science (GIScience) educational programs currently exist, the oldest now over 25 years. Offerings vary from those specifically focussed on geographic information science, to those that utilise geographic information systems in various applications and disciplines. Over the past two decades, there have been a number of initiatives to design curricula for GIScience, including the NCGIA Core Curriculum, GIS\&T Body of Knowledge and the Geospatial Technology Competency Model developments. The rapid developments in geospatial technology, applications and organisations have added to the challenges that higher educational institutions face in order to ensure that GIScience education is relevant and responsive to the changing needs of students and industry. This paper discusses some of the challenges being faced in higher education in general, and GIScience education in particular, and outlines a flexible higher education curriculum framework for GIScience.
\end{abstract}

\section{INTRODUCTION}

\subsection{General Overview}

Geographic information science (GIScience) education programs are now solidly embedded into educational institutions. Offerings range from the use and application of geographic information systems (GIS) applied within different disciplines such as geography or geology, to customisation of GIS tools and models for specific tasks such as environmental management or transportation modelling, to the advancement of GIScience concepts and knowledge including web mapping services and geocomputational modelling.

GIScience programs have developed over the past two to three decades and have undergone numerous evolutions and changes driven by both technologies and the increasing collaborations among users (Li, Veenendaal \& Dragicevic, 2011). Not only the rapid developments in technology, but also the application to a diverse range of disciplines and sectors has marked advancements in the geospatial field. The challenge for educators is to maintain the currency and relevance of GIScience curricula to meet the changing needs and demands of industry and government as well as students.

\subsection{Aim and scope}

This paper identifies some of the challenges being faced by higher education in the teaching and learning environment for GIScience. It then reviews some of the developments in GIScience curricula in higher education over the past few decades. A new framework for GIScience is proposed to address the challenges and provide a means to incorporate and embed rapidly evolving and new developments in a flexible educational environment.

The examples of the GIScience programs at Curtin University in Perth, Australia, are utilised given that Curtin is one of the earliest adopters of GIScience education at the higher education level. After more than two decades of offering GIScience education, these programs recently went through a comprehensive course review process which has served to initiate and inspire the curriculum research outlined in this paper.

\section{CHALLENGES CONFRONTING GISCIENCE HIGHER EDUCATION}

\subsection{Higher education trends driving change}

Higher education is presently undergoing many changes and developments. A recent Ernst \& Young report on the future of higher education in Australia identified that the thousand year old industry is on the cusp of profound change (Boker, 2012). They called on universities to specialise more to focus on particular student cohorts, to become more efficient in their education delivery model and to integrate with industry to differentiate their offerings.

In particular, Boker (2012) identified five main trends that are driving change in the higher education sector, namely, democratisation of knowledge and access, digital technologies, global mobility, integration with industry, and contestability of markets and funding (Figure 1). Each trend can be viewed from the perspective of GIScience education and influences the directions of curriculum development.

Unlike the traditional university model as the source of knowledge, this "knowledge" is now held online via the web and accessible globally to anyone who is connected. In regards to GIScience, there is a massive amount of material online that is accessible to countries and communities that have been previously unable to access such education, and this changes the way in which universities approach their teaching and learning environments, curricula and delivery.

Digital technologies have been transforming the way that education is delivered and supported for some time now. There are quite a number of education providers globally that deliver GIScience programs fully online and in distance mode. The 
challenge is to provide a holistic learning experience for students, even when they are not physically present in the classroom. For example, Curtin University has delivered its Graduate Certificate and Diploma programs in GIScience in both face-to-face and fully online, distance modes for over 13 years. Both modes are delivered simultaneously to give students a similar learning experience and the opportunity to engage and interact with each other in the learning process. An example of such engagement is the virtual field trip that involved distance students in almost identical learning experiences as on-campus students in vegetation mapping and GIS analysis (Veenendaal, Gulland \& Hall, 2005).

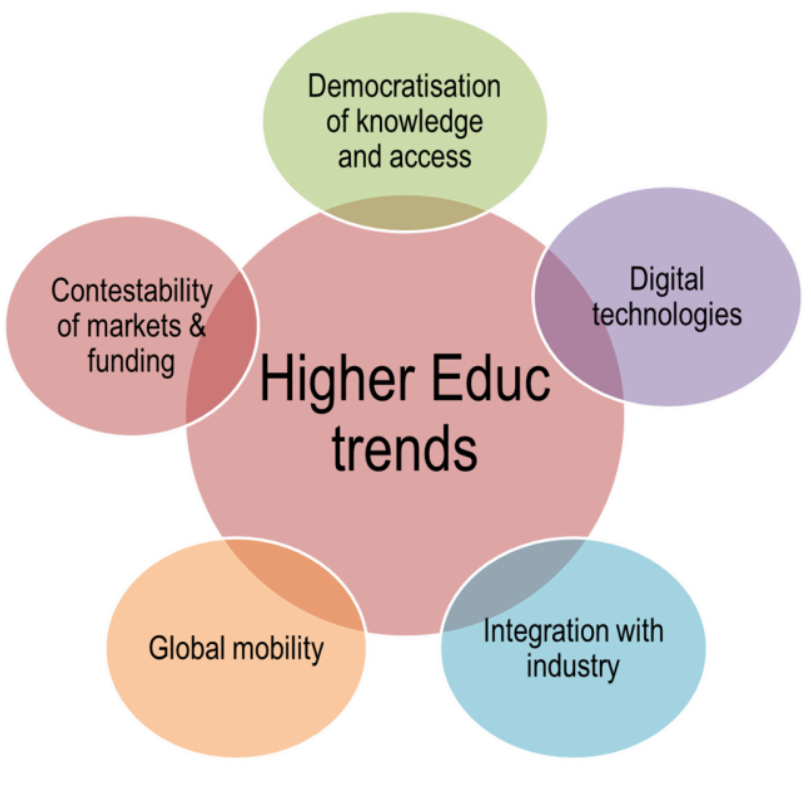

Figure 1: Trends in higher education (adapted from Bokor, 2012, p. 6)

Because of increasing global mobility, universities are able to access students and academics alike from the diverse global village in which we live. The increasing challenge is to accommodate this diversity in an educational environment that can respond to the needs and opportunities available globally. Students enter university with very different levels of knowledge and skills. Further, cultural diversity and different expectations need to be catered for in the educational offerings.

Educational institutions are continuing to increase and deepen relationships with industry both to strengthen the programs in terms of content and relevance, and to utilise the industry expertise in teaching and research developments. Industry plays a key role in identifying the knowledge and skills they are seeking from graduates and their future workforce. An example of a strong academic-industry partnership is the Cooperative Research Center for Spatial Information which is a government, industry and academic research joint venture "using spatial technologies to solve complex problems of national significance" (CRCSI, 2014).

Australian higher education institutions are funded via a demand-driven model. Hence it is important to build and maintain reputation and a marketing presence in a highly competitive market. GIScience is not seen as a highly visible career path and is largely unheard of among high school leavers and potential university students. Hence, universities are struggling to maintain student enrolments and economically viable programs in the GIScience disciplines. In Australia, apart from a few, most GIScience departments have been subsumed into other discipline areas to maintain viability and economic sustainability. The challenge is to increase the visibility of geospatial career pathways and the exciting opportunities and challenges they offer.

\subsection{Development of GIScience curricula}

The GIScience higher education programs have undergone many changes and developments over the past decades. For example, at Curtin University, the first offering was just over 25 years ago with the Graduate Diploma in Geographic Information Systems, as it was then termed. Then, in 1992, Curtin commenced its undergraduate offering, the Bachelor of Science (Geographic Information Systems), the first of its kind in the world. The term geographic information science was first coined in 1992 by Goodchild (1992) and defines the science and techniques that underpin geographic information systems.

The early GIS educational programs were defined by the learning resources that were available at the time. One of the early textbooks used in GIS education was that of Burrough (1986) which shaped many of the first curricula at colleges and universities, including that of the original program at Curtin University. Since then, the development of a number of curricula have taken place providing rich resources for educators to draw on (Figure 2).

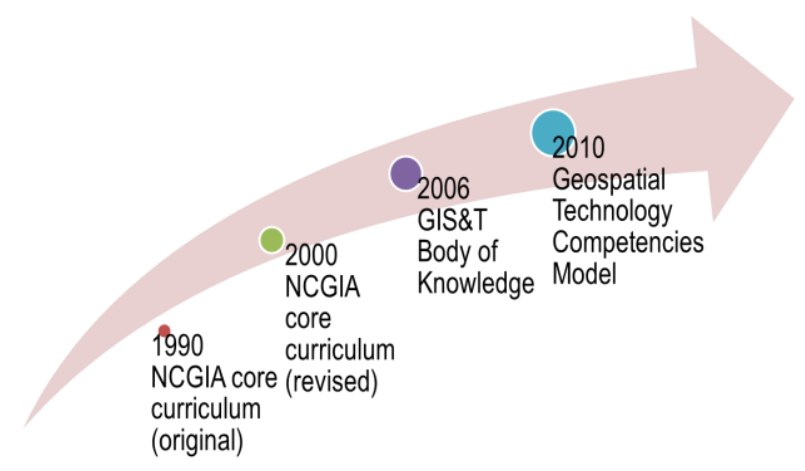

Figure 2: Development of GIScience Curricula

In 1990, the National Center for Geographic Information Analysis developed a core curriculum comprising content and lecture materials to assist educators in geographic information systems (Goodchild \& Kemp, 1990). The result of the effort was the NCGIA Core Curriculum which was made available as 75 units comprising notes and references. The NCGIA Core Curriculum was updated, revised and released in 2000 to incorporate feedback and suggestions, and to accommodate the rapid advances in technology (NCGIA, 2000).

With the fast moving developments in geospatial and information technologies, it was not long before the core curriculum became outdated in its breadth and range of content and knowledge. An effort coordinated by the University Consortium for Geographic Information Science (UCGIS) involved more than 70 educators and resulted in the development of the Geographic Information Science and Technology (GIS\&T) Body of Knowledge (BoK) (Dibiase et al, 2006). 
The GIS\&T BoK comprises the subdomains of geographic information science, geospatial technology and applications of GIS\&T. It includes contributions from allied disciplines such as geography, computer science, statistics, mathematics, landscape architecture, psychology and philosophy and can serve a wide range of disciplines and application domains that use or benefit from GIS\&T.

The BoK is intended to serve a range of educational program levels and pathways from primary/secondary education to higher and continuing education. It comprises ten knowledge areas divided into units representing coherent sets of topics which themselves represent a single concept, methodology or technique (Dibiase et al., 2006). Topics are defined in terms of educational objectives, of which there are 1660 in the BoK. These topics and objectives are not prescriptive, but can be utilised selectively and in different combinations for particular educational programs and pathways.

The Geospatial Technology Competencies Model (GTCM) was developed by the United States Department of Labor's Employment and Training Administration (DOLETA) in 2010. The 9-tiered model identifies general and specific competencies including foundational (Tiers 1-3), technical (Tiers 4-5), occupational (Tiers 6-8) and management (Tier 9) (DiBiase et al., 2010). The GTCM is linked to specific industry knowledge and skill needs and hence utilises competencies as a basic building block.

The GTCM is directly linked to specific needs and competencies required by the geospatial industry and sector and related to different occupations and specialisations across the spatial sciences (DOLETA, 2010). The occupational tiers are not more fully detailed in the model, but can be expanded in relation to specific associated occupations as found in the profiles listed on O-NET Online (O-NET, 2014).

The NCGIA core curriculum and the GIS\&T BoK initiatives are largely focussed on addressing the needs of GIS specialists and analysts, with an emphasis on the knowledge and skills of GIS technology and systems.

The BoK does go beyond the technology issues and incorporates infrastructure and society issues in relation to the usage and implementation of the technology in organisational and industry contexts. This is especially apparent through the GIS\&T and Society and the Organisational and Institutional Aspects knowledge areas with 13 units defined (Dibiase et al., 2006).

The GTCM links content to occupational tasks in the form of competencies. Hence it is not just another listing of content and disciplines, but links together personal, academic, workplace, industry, occupational and management competencies in an extensive and well defined framework model. The tiers in the model can then be further expanded and flexibly used in the context of particular industries and occupations. The model is two-dimensional but could be expanded in the third dimension to identify domain-specific competencies in the allied fields that utilise geospatial technology and professionals (DOLETA, 2010). The benefit of this model is that it accommodates opportunities where industry linkages could occur and where the geospatial program offerings can benefit from increased industry engagement.

\section{FRAMEWORK FOR GISCIENCE HIGHER EDUCATION}

\subsection{Framework requirements and scope}

In order to address the higher education challenges for GIScience in the context of the trends at a higher education level, a curriculum framework was developed for GIScience. It needed to utilise and take advantage of the past work done on GIScience curricula, as well as be able to cater for increasingly diverse student needs and markets, as well as the changing demands and opportunities associated with teaching and learning environments.

The curriculum framework needed to be just that, a framework, and not a prescriptive list of topics. At the same time, the framework can be implemented in different educational programs at different levels to cater for varying students and industry needs. Further, the framework does not specify the mode of delivery and can be utilised within a range of educational delivery mechanisms including face-to-face, fully distance, online and flexible study modes.

\subsection{GIScience higher education curriculum framework}

The GIScience higher education curriculum (HEC) framework was developed by Curtin University and is illustrated in Figure 3. It is introduced by Veenendaal (2014) in the context of three eras of development of GIScience higher education, namely, GI systems in the 1990s, GI Science in the 2000s and GI Integration in the 2010s. These eras of development have provided a foundation to specify a new curriculum framework for GIScience. This paper discusses the new framework in the context of the broader higher education trends which give an indication of the directions that GIScience higher education are taking and will continue to take.

The GIScience HEC framework was developed by utilising the tiered concepts of the GTCM model, especially in distinguishing the academic and workplace elements of the curriculum. It does not specify the content as the NCGIA and BoK initiatives do. Rather, the existing content-based curricula developments, such as the GIS\&T BoK, can be used to specify and organise content within the framework identified. In the context of the trend of increasing democratisation of knowledge and access, the content will continue to evolve and develop, and increasing utilise a range of online sources and resources in its development. Hence, the framework does not specify this content nor its sources, but accommodates a changing geospatial knowledge environment.

The GIScience HEC framework comprises four tiers which identify knowledge and skills groupings that need to be incorporated into a curriculum based on the graduate attributes required by an education program.

Tier 1 of the framework comprises academic knowledge and skills. This tier involves generic communication and literacy skills such as reading/writing, speaking/listening, mathematics/statistics, critical \& analytical thinking, computer literacy and appreciation of people and places. Depending on the entry level required by the educational program, it can be assumed that student cohorts will have some of these skills and knowledge. The extent of the skills and knowledge required will vary by program and likewise the extent of what the program incorporates. 


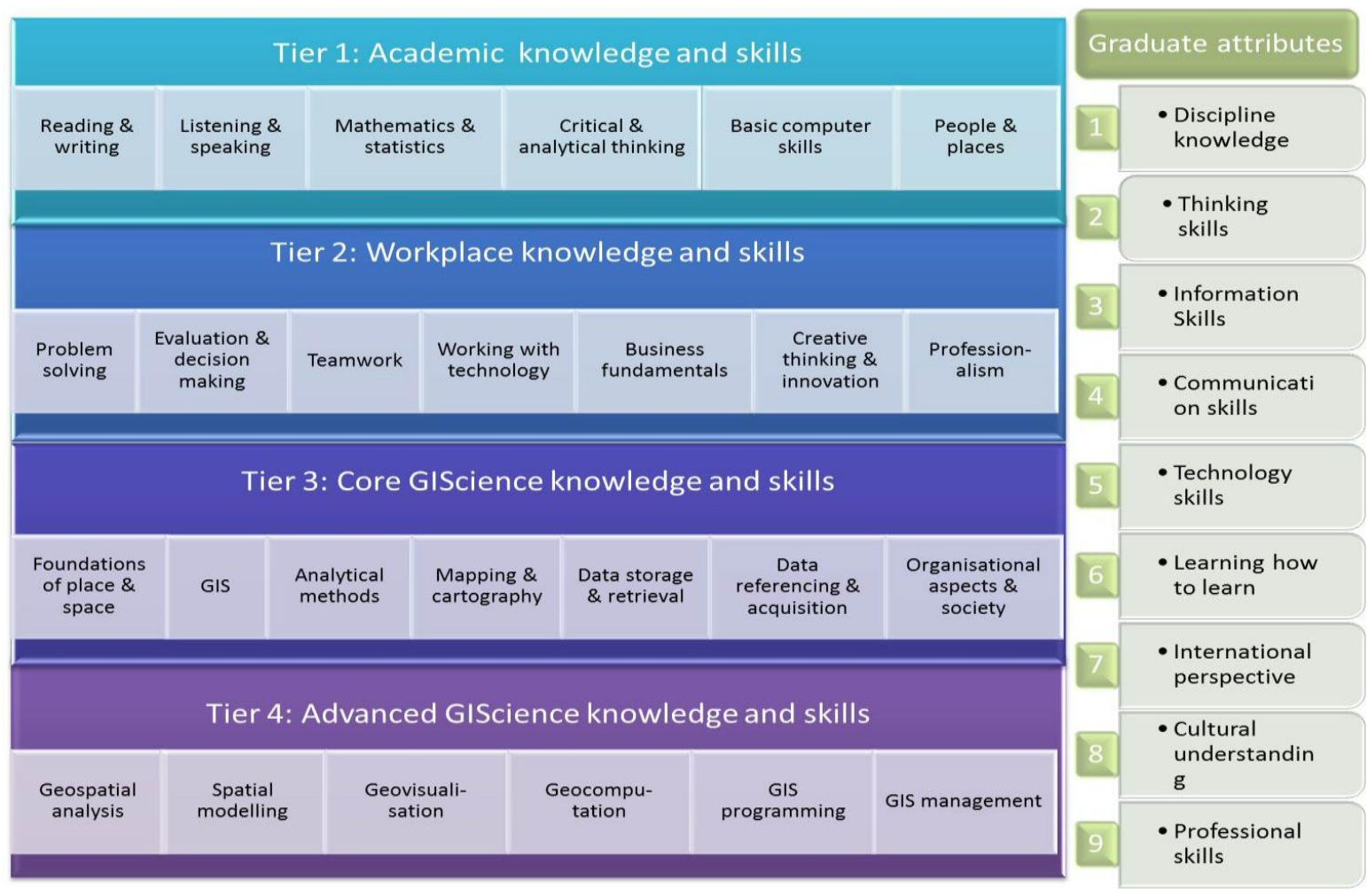

Figure 3: GIScience higher education curriculum framework

The second tier of the framework deals with the skills and knowledge required in the workplace. This includes such aspects as problem solving, teamwork, business fundamentals and professionalism. Student cohorts with backgrounds in the workplace or in other disciplines may have many of these skills already, whereas students freshly out of secondary school and entering an undergraduate degree may lack almost all of this knowledge and skills.

The core GIScience knowledge and skills are identified in the third tier of the framework. These identify the core areas of the discipline that all GIScience programs will draw on. They include the foundations of geography (place and space), GIS basics, analytical methods, mapping, data storage and retrieval, data referencing and acquisition, and organisational aspects and society. Although all programs should comprise these core elements, the level of detail will vary among different programs and student cohorts. For example, geology students requiring geospatial knowledge and skills would draw on topics within each of these core areas, but the knowledge of GIS utilisation or types of data acquisition may vary from a health student doing epidemiological tracking and mapping.

More advanced GIScience knowledge and skills are captured in Tier 4 of the model. These are embedded more commonly in specialist GIScience programs or disciplines requiring strong skills in geospatial analysis and modelling. Advanced skills and knowledge comprise geospatial analysis, spatial modelling, geovisualisation, geocomputation, GIS programming and customisation, and GIS management.

The framework also identifies the graduate attributes towards which the curriculum must be directed. The graduate attributes shown in the model are relatively generic, but are taken from those adopted by Curtin University (Curtin, 2014). They may vary somewhat from institution to institution, and can be replaced as necessary.

This framework specifies the groupings of knowledge and skills at each tier, but does not specify the topics and units that deliver the knowledge and skill groupings. However this is where the GIS\&T BoK was utilised and expanded where necessary to develop the content appropriate to a particular course offering. It is expected that different course offerings and different institutions would "package" these knowledge and skills in their own unique program structure that bears the stamp and reputation of their own higher educational institution and academic/research staff profiles. This is the manner in which higher educational institutions are differentiated.

\subsection{Applying the framework model to higher education trends}

Because the GIScience HEC model is a framework and not a content specification like the GIS\&T BoK, it allows for the fact that knowledge and skills can continue to grow and evolve in a geospatial education environment. The tiered structure of the framework identifies the broad attributes of knowledge and skills and allows existing and new content and applications to be applied. The source of knowledge and how it is applied in a teaching context and engaged with by learners is outside of the framework and can be used as a means for institutions to differentiate themselves.

It is ironic that, in a sense, the digital technologies that increasingly underpin higher education are also the digital technologies that form part of the knowledge and skills in GIScience education. For example, the web is not only a 
repository of learning resources, but also a means to engage and interact in learning knowledge and obtaining skills. Similarly, geospatial applications increasingly access a web that is not only a repository of geospatial information, but provides services and resources with which geospatial applications can engage. An obvious example of this is the growing field of web GIS and geoprocessing web services that are increasingly becoming integrated into online geospatial solutions and workflows. At the same time, web GIS provides an online platform that is accessible to, and able to engage geographically disparate learners in a flexible learning environment.

In this day and age of increasing mobility, the higher educational offerings need to cater for a wide diversity of students entering university with a broad range of backgrounds and prior knowledge and skills. The tiered framework provides a means of incorporating different levels of knowledge and skills, including those that are not discipline-specific, and including those that are obtained prior to commencing a university level program. Different educational programs can therefore focus on different attributes from the tiers of the framework that apply to the specific cohort of students being targeted by the program.

For example, an undergraduate GIScience bachelor degree will assume much less of the Tier 1 Academic knowledge and skills attributes than will a Masters level degree because of the different expected prior knowledge of high school students versus mature age students with professional qualifications. Further, a Masters level program may also expect students to have more of the Tier 2 Workplace and Tier 3 Core GIScience attributes as prior knowledge and skills and focus on the Tier 4 Advanced GIScience attributes within the program. Conversely, a bachelor program may focus more on the Tier 1 Academic and Tier 3 Core GIScience attributes in the earlier part of the program, with a view towards more Tier 2 Workplace knowledge and skills in the advanced years of the program. Veenendaal (2014) explains this further by applying the framework to various program offerings at both undergraduate and postgraduate levels.

An important component of the competitiveness and reputation of higher educational offerings is the relevance, currency and alignment of their educational offerings to real world workplaces and industry requirements for personnel knowledge and skills. Traditionally, this has been closely tied to the knowledge and experience of teaching academics and the exposure of students to the real world workplace often near the end of the program and prior to graduation. However, the GIScience HEC framework provides a separate tier, Tier 2 Workplace knowledge and skills, that identifies attributes required by the workplace and which need to be embedded throughout the curriculum.

To illustrate this with an example, the Problem solving attribute is embedded in a first year computer programming unit within the Bachelor of Science (GIScience) degree at Curtin University, whereas the Creative thinking \& innovation and the Teamwork attributes are worked out in second and third year units. Additionally, an internship unit in the final year of the 3year program provides opportunity to further develop the Business fundamentals and Professionalism attributes within Tier 2 of the framework.

Finally, the market competition and need to sustain funding for GIScience higher education programs is an important driver regarding the directions of curriculum development. Especially in the GIScience discipline, the markets are extending far beyond the traditional industries that have been more aligned to mainstream geospatial products and applications. GIScience knowledge and skills are now being required by a wide range of professions and disciplines including planning, health, resources, agriculture, business development, disaster management and infrastructure planning, etc. Hence, the curriculum must also adapt to the needs of learners who may not be aiming for a "geospatial" career pathway, but may embed and integrate geospatial skills as necessary components within their core (non-geospatial) discipline pathways.

As an example, the first year core unit introducing geographic information systems, taught traditionally within the Bachelor of Science (GIScience) degree at Curtin University, now also features across multiple programs in other disciplines such as surveying, mine engineering, environmental geoscience, petroleum geology, etc. Hence, various combinations of Tier 1, Tier 2 and Tier 3 attributes need to be integrated to provide an introductory GIS unit that is problem-based with regards to its application, provides the necessary People \& places background knowledge and skills, and yet brings across the core GIS and mapping attributes to be able to use and apply the technology to discipline specific problems and applications.

\section{SUMMARY AND CONCLUSIONS}

Given the trends in higher education and the challenges that arise coupled with rapid developments in geospatial technology and applications, it is important for GIScience curriculum to adapt and meet arising needs and demands. Understanding the diversity in student backgrounds, need for industry-ready graduates, and expanding geospatial knowledge and technology are necessary to be able to address curriculum development in a global, changing and competitive educational environment.

The GIScience HEC framework provides a flexible approach to addressing such curriculum developments. It provides a foundation from which the curricula for different educational programs can be developed and revised to cater for different student cohorts with diverse backgrounds, differing needs, and headed along different career pathways. The tiered model and associated attributes provide a means to build and structure a curriculum with the capacity to extend the underlying knowledge and skills that come with the growing and expanding geospatial industry.

As higher education institutions continue to provide and develop GIScience programs and offerings, the GIScience HEC framework can provide a means of reviewing and revising the curriculum in response to higher education challenges and geospatial community needs. Past curriculum developments, especially those of the GIS\&T BoK and GTCM, providing a body of knowledge and geospatial competencies model, respectively, can be integrated and expanded within the context of the framework to address the diverse and growing community requiring geospatial knowledge and skills. In this way, the GIScience curriculum will be able to withstand the fast-developing technologies and challenges, and continue to serve the ever-expanding industries, both geospatial and beyond. 


\section{REFERENCES}

Boker, Justin. 2012. University of the future: A thousand year old industry on the cusp of profound change. Ernst \& Young. http://www.ey.com/Publication/vwLUAssets/University_of_the _future/\%24FILE/University_of_the_future_2012.pdf (25 Mar 2014).

Burrough, P.A. 1986. Principles of Geographical Information Systems for Land Resources Assessment. Oxford University Press, ISBN 0198545924.

CRCSI. 2014. Cooperative Research Center for Spatial Information. http://www.crcsi.com.au (15 Mar 2014).

Curtin. 2014. Curtin Graduate Attributes. Curtin Teaching and Learning, Curtin University, Perth, Western Australia. http://otl.curtin.edu.au/learning_teaching/graduate_capabilities. cfm (15 Jan 2014).

DiBiase, David, Michael DeMers, Ann Johnson, Karen Kemp \& Ann Taylor Luck (editors). 2006. Geographic Information Science and Technology Body of Knowledge. Association of American Geographers, Washington, USA.

DiBiase, David, Tripp Corbin, Thomas Fox, Joe Francica, Kass Green, Janet Jackson, Gary Jeffress, Brian Jones, Brent Jones, Jeremy Mennis, Karen Schuckman, Cy Smith, \& Jan Van Sickle. 2010. The New Geospatial Technology Competency Model: Bringing Workforce Needs into Focus. URISA Journal, 22:2.

DOLETA. 2010. Geospatial Technology Competency Model. Employment and Training Administration, United States Department of Labour, http://www.careeronestop.org/CompetencyModel/pyramid.aspx ?GEO=Y (1 Jan 2014).

Goodchild, M.F. 1992. Geographical information science. International Journal of Geographical Information Systems, 6:1, pp 31-45.

Goodchild, M.F., and K.K. Kemp, eds. 1990. NCGIA Core Curriculum in GIS. National Center for Geographic Information Analysis, University of California, Santa Barbara CA. http://www.geog.ubc.ca/courses/klink/gis.notes/ncgia/toc.html (15 Jan 2014).

Li, S, B Veenendaal \& S Dragićević. 2011. Advances, challenges and future directions in web-based GIS mapping services. In Li, S, Dragićević, S and Veenendaal B (2011) Advances in Web-based GIS, Mapping Services and Applications, Taylor \& Francis Group, London, ISBN 978-0415-80483-7.

NCGIA. 2000. The NCGIA Core Curriculum in GIScience. National Center for Geographic Information Analysis, University of California, Santa Barbara CA. http://www.ncgia.ucsb.edu/giscc/aboutgiscc.html (15 Jan 2014).

O-NET. 2014. O-NET OnLine: Find Occupations. O-NET OnLine, a partner of the AmericanJobCenter network. http://www.onetonline.org/find (15 Jan 2014).

Veenendaal, Bert. 2014. Development of a Flexible Higher Education Curriculum Framework for Geographic Information Science. ISPRS Annals, ISPRS Technical Commission IV Symposium on Geospatial Databases and Location Based Services, 14-16 May, Suzhou, China.
Veenendaal, B., E. Gulland and D. Hall. 2005. Developing Authentic and Virtual E-learning Environments. ISPRS Archives, Proceedings of the ISPRS Workshop Commission VI/1-VI/2, Tools and Techniques for E-Learning, Potsdam, Germany, June 1-3. http://www.isprs.org/proceedings/ XXXVI/ 6-W30/Paper/eLearnWS_Potsdam2005_Veenendaal.pdf $\quad(25$ Mar 2014).

\section{ACKNOWLEDGEMENTS}

Through its comprehensive course review (CCR) process, Curtin University provided the opportunity to review and reflect on the GIScience curriculum developed over several decades. The contribution and assistance of colleagues in the Department of Spatial Sciences and the Curtin Teaching and Learning group as well as student feedback and evaluations are gratefully acknowledged. I also would like to express my appreciation to the ISPRS and ICA for providing the opportunity to share our curriculum experiences with a broader audience. 